\title{
RESENHA DE BRÁS CUBAS AUTOR, MACHADO DE ASSIS LEITOR, DE REGINA ZILBERMAN
}

\author{
REVIEW OF BRÁS CUBAS AUTOR, MACHADO DE ASSIS \\ LEITOR, BY REGINA ZILBERMAN
}

ZILBERMAN, Regina. Brás Cubas autor, Machado de Assis leitor. Ponta Grossa, PR: Editora UEPG, 2012. 249 p.

Juracy Assmann Saraiva

Universidade Feevale, CNPq e Fapergs

Novo Hamburgo (RS), Brasil

A singularidade do título do livro de Regina Zilberman, uma das mais importantes críticas de literatura da atualidade, corresponde ao original ângulo com que diferentes aspectos da obra de Machado de Assis são analisados. Assim, o lançamento da pesquisadora não apenas se soma à alentada fortuna crítica sobre a obra do escritor brasileiro, mas a ela agrega pontos de vista inovadores que a atualizam e enriquecem. Valendo-se de sólidos fundamentos teóricos - provenientes da Teoria da Literatura, da História da Literatura, da Sociologia da Leitura, da Estética da Recepção - e do conhecimento da produção machadiana, Zilberman investiga o processo criativo de Machado e relaciona-o ao sistema da literatura ocidental, sem descurar do contexto sociocultural sobre o qual o escritor lança seu olhar crítico.

Brás Cubas autor, Machado de Assis leitor apresenta duas partes distintas, cujos ensaios são unificados pela acuidade da leitura da ensaísta. A primeira parte enfoca Memórias póstumas de Brás Cubas sob uma perspectiva histórica para restabelecer o diálogo da obra com a tradição literária, com manifestações de identidade e com representações da sociedade brasileira do século XIX, procedimento que conduz à explicitação de estratégias composicionais do romance, as quais abrem espaço para reflexões sobre a concepção de autoria, sobre fontes primárias e sobre a presença de personagens flâneur na ficção de Machado. 
No ensaio inicial, "Brás Cubas herói fundador", Zilberman elucida as razões que sustentam a ruptura de paradigmas estéticos inscrita em Memórias póstumas de Brás Cubas, estabelecendo um paralelo entre aspectos da composição do romance e ideias expressas nos textos críticos "O primo Basílio" e em "A nova geração", vistos como "manifestos particulares, em que Machado de Assis discordava dos caminhos tomados pela literatura" (p. 18). Nesse sentido, o alinhamento à ficção produzida por Sterne e Maistre representaria "a eleição de um modelo literário, com as devidas implicações estéticas" (p. 21), traduzidas, particularmente, pela problematização da situação narrativa, em que o narrador e o autor do livro convergem, processo que atenderia ao interesse de Machado de Assis em "delegar a autoria de Memórias póstumas a Brás Cubas, o sujeito que primeiramente as subscreve" (p. 25), e que enfatizaria o comportamento de Machado como leitor de obras em circulação.

A autora investiga, também, as implicações decorrentes do "Prólogo" das Memórias, incluído na quarta edição, justificando-o pela necessidade que Machado teve de esclarecer o enquadramento da obra ao gênero romance, diante da dificuldade dos receptores em assimilar a novidade de sua forma. Em outro ensaio, Zilberman vale-se da versão em folhetim de Memórias póstumas de Brás Cubas - que, na falta dos manuscritos, detém o estatuto de fonte primária - para examinar as modificações introduzidas por Machado nas três edições em livro desse romance. A ensaísta conclui que a continuada reescrita expõe a concepção poética do escritor, já que permite depreender "o programa que rege a elaboração do romance, sobre o qual o controle é exercido e as reações, manipuladas" (p. 82).

As fontes de pesquisa são outro tópico em que Regina Zilberman se detém, preocupando-se em esclarecer as noções de memória, arquivo e testemunho. No caso de Machado de Assis, o "labor poético" (p. 107), que se expõe na reedição dos textos, seria testemunho de suas opções artísticas, sendo uma espécie de espólio que possibilita identificar o aperfeiçoamento do escritor, visível na distância formal que separa Contos fluminenses e Memórias póstumas de Brás Cubas.

Por considerar que Memórias póstumas de Brás Cubas é "o principal investimento literário de Machado de Assis" (p. 109) - em que sua rejeição à poética realista é mais evidente -, a ensaísta analisa os textos críticos de Machado, publicados 
em $O$ Cruzeiro, em que esse aponta defeitos na construção dos romances $O$ crime do padre Amaro e O primo Basílio. Segundo Zilberman, ao escrever Memórias póstumas, os romances de Eça constituíram, para Machado, um paradigma às avessas, cujas falhas não deseja repetir, o que se constata no tratamento dado ao tema e em decisões técnicocomposicionais.

Consequentemente, Zilberman confirma a importância que as obras literárias em circulação no século XIX têm para o processo criativo de Machado de Assis, uma vez que, em sua escrita, ele "atua retrospectivamente, construindo sua poética a partir de sugestões advindas de suas leituras" (p. 122). Paralelamente, enfatiza as frequentes correções a que o ficcionista submete seus próprios textos, o que permite concluir que, para ele, a obra é um processo inacabado, concepção que atinge também a imagem do autor, que, a partir das leituras de sua obra, está em um movimento contínuo de construção.

Entretanto, nessa mobilidade, o leitor exerce importante papel, pois, como ele também é móvel, a contínua mudança de horizontes abre novas possibilidades de interpretação da obra. Isso justifica a releitura de narrativas machadianas segundo a perspectiva de Walter Benjamin e a partir dos pressupostos da Estética da Recepção. No primeiro caso, Zilberman acompanha o perambular de Brás Cubas e do conselheiro Aires, para referir que cenários - instalados por meio da percepção de seu olhar - se sobrecarregam de um posicionamento moral, cujo registro cabe ao leitor apreender. Essa propriedade discursiva confere, segundo Zilberman, o estatuto de alegorista ao escritor fluminense, uma vez que expõe a degradação da sociedade brasileira, regida pelo capitalismo, sem que seus personagens denunciem a "face mercadológica da arte", porque nem Brás nem Aires são representados como artistas, deixando de "coincidir o flâneur e o escritor" (p. 147).

O segundo grupo de ensaios enfatiza o tema da leitura, seja a que Machado de Assis faz de sua própria obra, seja a efetuada por seus receptores e que sobrecarregam os textos com novas significações. Zilberman retoma as discussões, geradas por "Confissões de uma viúva moça" - conto publicado no Jornal das Famílias, em 1865, na forma de folhetim, quando o escritor era ainda um neófito no âmbito da ficção - e afirma que a polêmica, veiculada por jornais, teria conferido grande visibilidade ao 
texto e ao meio que o divulgava, mas, igualmente, teria exigido uma atitude de contenção por parte de Machado, motivada pelo público leitor que ele pretendia conquistar.

Essa atitude, de acordo com a ensaísta, é verificável em Helena, em que o proibitivo tema da atração incestuosa serve para "analisar a índole das regras sociais, que existem para manter a aparência de normalidade e probidade a ser transmitida pelo comportamento das pessoas" (p. 170). Ao se orientar para esse objetivo, Machado constrói a narrativa por meio de estratégias que instituem a oscilação entre o encobrimento e a revelação das significações textuais, traço que lhe facultaria instalar, em Helena, uma sutil crítica à organização social. Entretanto, ao restringir o acesso do público à compreensão do mundo representado, resguardando seu posicionamento autoral por meio de sutilezas e artifícios, Machado de Assis teria escolhido "o meio termo" para seu livro, "emanando, desde então o sentimento de transitoriedade com que a crítica cristalizou sua imagem" (p. 180).

A análise da recepção de Machado é outro tema do livro. Zilberman identifica a divisão em fases, a articulação entre elas e o aperfeiçoamento contínuo como características da obra sublinhadas pelos críticos contemporâneos ao escritor, concepção endossada pelo próprio Machado que, afirma Zilberman, "se torna, nesta medida, prisioneiro de sua própria cronologia" (p. 186). Essa afetaria a recepção de Helena, que recebe o qualificativo de romance desatualizado, embora ofereça a possibilidade de estabelecer um diálogo com o leitor atual pela comparação entre a situação apresentada e a contemporânea.

Ao centrar-se em "O caso da vara", Zilberman parte do princípio de que o diálogo entre o texto literário e o leitor "acontece em dois níveis: o mimético e o simbólico" (p. 192). Sem limitar a análise do conto "à reprodução realista de uma situação," a autora evidencia o caráter pedagógico da narrativa que "ensina ao leitor que um ser humano, dotado de poder absoluto, age de forma extremamente violenta contra seu semelhante" (p. 196). Assim, transcende as leituras miméticas do conto, que o limitam ao contexto da sociedade brasileira do século XIX, para recuperar sua dimensão simbólica, reveladora da complexa natureza do ser humano, cujas características não têm limites geográficos ou temporais. 
Em "Dom Casmurro no horizonte de sua recepção", Zilberman expõe a atitude contraditória dos leitores em face dessa obra, explicando-a por meio das informações que sobre ela circulam, geradoras de pré-conceitos ou preconceitos capazes de inibir a fruição do texto. Para a crítica, duas são as atitudes diante do romance: curiosidade e interesse, motivados pelo conhecimento prévio de traços das personagens Bentinho e Capitu, traços que, confrontados com a representação textual, frequentemente dela divergem, frustrando o leitor; reverência e distanciamento, decorrentes da percepção de Dom Casmurro como um "objeto de culto", cuja compreensão estaria fora do alcance dos leitores comuns. Portanto, "Dom Casmurro é uma obra que carrega consigo marcas que antecipam sua leitura" (p. 214), as quais levam a ensaísta a concluir que essa obra "colabora para o fortalecimento das teses que não abrem mão de entender as respostas de seu público" (p. 218), uma vez que esse atua no modo como a obra literária circula na sociedade.

O título "De Machado de Assis a Graciliano Ramos: memória e ficção na

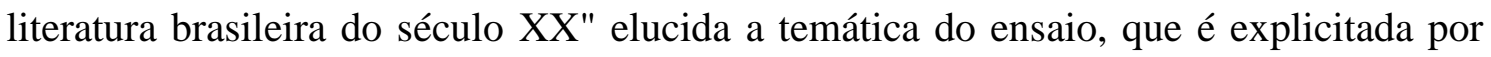
meio da recuperação do gênero memorialístico na literatura ocidental. Zilberman afirma ser Manuel Antônio de Almeida, com a publicação de Memórias de um sargento de milícias, o precursor do gênero no Brasil e Machado de Assis, com Memórias póstumas de Brás Cubas, seu sucessor. Com essa obra, o escritor fluminense teria inovado o gênero memorialístico, circunstância que repetiria ao introduzir, em Dom Casmurro, a reflexão "sobre os processos que caracterizam a recordação" (p. 223). O procedimento aproximaria esse romance de São Bernardo, que conjugaria as lembranças sobre Dom Casmurro e as de Paulo Honório, o qual também analisa as circunstâncias que acionam sua escrita. Segundo a autora, a fala de Paulo Honório "situa-se em um limite além do qual se coloca a ruptura da linguagem, tal como procede Riobaldo, herdeiro do legado que se transmite de Machado a Graciliano Ramos e desemboca em Guimarães Rosa, de Grande Sertão" (p. 233). Essa transformação alteraria, igualmente, a concepção de memória, cujo discurso já não recupera a trajetória pregressa de um indivíduo, mas busca converter o inconsciente em linguagem. ${ }^{1}$

\footnotetext{
${ }^{1}$ Regina Zilberman publicou uma primeira versão desse ensaio no número 2 da revista Machado de Assis em Linha, disponível em <http://machadodeassis.net/download/numero02/num02artigo09.pdf.>. Acesso em 07.12.2012.
} 
O último ensaio, "Sexual/idade: preconceito e liberação em Memorial de Aires", apoia-se na verticalidade da leitura por meio da qual a autora desvenda citações extraídas de obras artísticas e estabelece um paralelo entre outras criações poéticas e o Memorial, para demonstrar que a paixão do Conselheiro por Fidélia não se limita à exaltação estética, mas que ela é reprimida pelos preconceitos a que o próprio protagonista se submete. Segundo Zilberman, com essa obra memorialística, Machado deixa "ao leitor a tarefa de refletir sobre ideias preconcebidas e redutoras que acabam por prejudicar o sujeito que as compartilha" (p. 249) e "parece reivindicar [...] um lugar para o idoso" que não pode ser confundido com o morto ou acabado.

Com Brás Cubas autor, Machado de Assis leitor, Regina Zilberman traz a público uma obra em que ângulos originais da produção machadiana são explicitados, mas em que, igualmente, o sistema da literatura ocidental é revisto, sendo oferecida aos leitores uma visão enriquecedora do escritor brasileiro, a qual a ele transcende. Além disso, o aparato teórico e o rigor crítico - que não se confundem com o hermetismo da linguagem - demonstram que os avanços teóricos da literatura são fundamentais para ampliar o conhecimento das produções dos escritores e para contribuir com o processo de renovação da criação estética. Portanto, Brás Cubas autor, Machado de Assis leitor é uma obra imprescindível não só para os estudos machadianos, mas também para o campo da literatura como um todo.

Juracy Assman Saraiva é pós-doutora pela Unicamp, professora e pesquisadora da Universidade Feevale, de Novo Hamburgo. É autora de $O$ circuito das memórias: narrativas autobiográficas romanescas de Machado de Assis. São Paulo: Edusp; Nankin, 2009. E-mail: <juracy@feevale.br> 